penetrance. If this is so the genetic background of these malformations is not likely to be elucidated for a long time. It would be unfortunate if preoccupation with this relatively unimportant aspect of the problem distracted attention from the much more pressing need to identify the environmental influences.

\section{Glycogen Storage Disease}

S. van Creveld ${ }^{1}$ and E. von Gierke ${ }^{2}$ first reported the clinical and post mortem findings in the hepatomegalic type of glycogen storage disease 40 years ago. Only in the last 15 years, however, have such cases, the symptomatology of which may be broadly similar, been differentiated into at least three types caused by congenital deficiencies of specific enzymes concerned in the breakdown of glycogen to glucose. These enzymes are glucose 6-phosphatase, amylo-1,6-glucosidase (debranching enzyme), and phosphorylase, deficiencies of which give rise, respectively, to types I, III, and VI glycogen storage diseases in the aetiological classification of G. T. Cori. $^{3} 4$

The term von Gierke's disease is now usually restricted to the type I disease, descriptions of which have appeared in many reviews. ${ }^{4}$ Abdominal enlargement is usually noticed in the first year of life and may be present at birth. Growth is markedly retarded, there is a tendency to adiposity, particularly of cheeks and breast, and eruptive xanthomata may occur. The massive enlargement of the liver, which often extends below the umbilicus, may give rise to pronounced lordosis, but portal hypertension and splenomegaly are rarely noted. Apart from carbohydrate metabolism hepatic function is usually unimpaired. Even when there is gross enlargement of the kidneys, with infiltration of the renal tubules by glycogen, surprisingly little abnormality of renal function may be detected, though glycosuria and non-specific aminoaciduria are sometimes noted.

Laboratory investigation shows marked fasting hypoglycaemia, often below $10 \mathrm{mg}$. true glucose $/ 100 \mathrm{ml}$. blood, but clinical signs and symptoms of hypoglycaemia may be absent, and mental development is generally normal. Hyperlipidaemia is often so pronounced that compensatory volume corrections are necessary in the determination of plasma constituents. Acetonaemia and acetonuria, usually related to episodes of acidosis, may be present, and the blood lactate concentration is usually high and increases considerably after the administration of adrenaline or glucagon. Blood urate levels are often raised because of the reduced renal clearance for urate in the presence of persistent lactic acidosis, and this may lead to manifestations of gout in patients who survive for a long time.

\footnotetext{
' van Creveld, S., Nederlansch Tijdschrift voor Geneeskunde, 1928, 72, 5283.

2 von Gierke, E., Beitrage zur Pathologischen Anatomie und zur Allgemeinen Pathologie, 1929, 82, 497.

s Cori, G. T., Moderne Probleme der Pädiatrie, 1957 3, 344.

- Field, R. A., in "The Metabolic Basis of Inherited Disease," 2nd ed. (edited by J. B. Stanbury, J. B. Wyngaarden, and D. S. Frederickson), 1966, p.p. 141-177. New York, McGraw-Hill.

- Hug, G., fournal of Pedriatrics, 1962, 60, 545.

6 Schwartz, R., Ashmore, J., and Renold, A. E., Pediatrics, 1957, 19, 585.

Hers, H. G., and Malbrain, H., Moderne Probleme der Pädiatrie, 1959, 4, 203.

8 Huijing, F., Clinica Chimica Acta, 1964, 9, 269.

Williams, H. E., and Field, J. B., fournal of Clinical Investigation, 1961, 40, 1841.

10 Sidbury, J. B., Gitzelmann, G., and Fisher, J., Helvetica Paediatrica Acta, 1961, 16, 506.

11 Field, J. B., Epstein, S., and Egan, T., fournal of Clinical Investigation, 1965, 44, 1240 .
}

Functional tests of carbohydrate metabolism may lead to a presumptive diagnosis by differentiation of the responses to be expected in the various hepatomegalic types. The absence of a normal hyperglycaemic response to the glycogenolytic action of adrenaline or glucagon in the fasting state is usually found in all the hepatomegalic types. Similar tests ${ }^{5}$ performed after a meal often help to differentiate types I and III, since feeding leads to the synthesis of new outer chains of glycogen, and these may give rise to a substantial increase in blood glucose after glucagon in type III disease, but will remain unavailable as glucose 6-phosphate in type I disease.

A further test, particularly useful in the diagnosis of type I disease, relies on the conversion of infused galactose ${ }^{6}$ or fructose ${ }^{7}$ into glucose. Glucose 6-phosphatase is essential for this conversion, so that the absence of a hyperglycaemic response to the infusion of these sugars is a good indication of its absence.

These tests provide information that may lead to an almost conclusive diagnosis in certain cases, and they are particularly useful in suggesting the most important estimations to perform on the small amount of liver obtained by needle biopsy ; but a complete definitive analysis covering glycogen content and structure and all relevant enzyme activities is often necessary, and this requires about $1 \mathrm{~g}$. of tissue taken at laparotomy. Biopsy of muscle from the abdominal wall should be done at the same time for the investigation of muscular involvement in cases of type III disease. If they are frozen at once tissues may be kept for months without deterioration of enzyme activities.

During recent years the use of blood cells for enzyme assay has provided an attractive alternative to surgical biopsy, and has provided opportunities for the biochemical investigation of modes of inheritance of these diseases. Thus leucocyte assays may detect the enzyme deficiencies in types III $^{8}$ and VI, ${ }^{9}$ and the erythrocyte glycogen content is usually increased in these types. ${ }^{10}$ It has been reported ${ }^{11}$ that the glucose 6-phosphatase deficiency may be detected in intestinal mucosa obtained by peroral biopsy of patients with type I disease. This alternative to liver biopsy may find wider use in the future diagnosis of other types of glycogen storage disease.

With the recognition of the fundamental biochemical abnormalities of type I disease rational defensive therapy in infancy may ensure relatively long survival for these patients. Frequent small feeds of glucose-containing carbehydrate throughout the day and night protect against severe hypoglycaemia, and the early recognition and vigorous treatment of infection and acidosis can avert life-threatening crises.

\section{Fellowships for General Practitioners}

To get away for a few months' study leave in middle life can be a most refreshing experience for the professional man. Perhaps of no one is this truer than the general practitioner, tied as he often is by his lifework to a particular locality. Recognizing this, the Nuffield Foundation is offering fellowships now of two to six months' duration to general practitioners, preferably between the ages of 35 and 45 , to undertake approved study overseas during 1970 of some subject of importance to general practice. The scheme is run in cooperation with the Royal College of General Practitioners, and it includes financial provision of locum assistance in the practice. Details can be found on advertisement page xxxi. 